This is an accepted manuscript of an article published by Taylor \& Francis in The Communication Review on 9th September 2011 (online), available online:

http://wwww.tandfonline.com/doi.org/10.1080/10714421.2011.597250.

To cite or quote please refer to the published article: Alexandra Segerberg \& W. Lance Bennett (2011). Social Media and the Organization of Collective Action: Using Twitter to Explore the Ecologies of Two Climate Change Protests, The Communication Review, 14:3, 197-215 


\title{
Social Media and the Organization of Collective Action: Using Twitter to Explore the Ecologies of Two Climate Change Protests
}

\author{
Alexandra Segerberg \& W. Lance Bennett
}

The Twitter Revolutions of 2009 reinvigorated the question of whether new social media have any real effect on contentious politics. In this article, the authors argue that evaluating the relation between transforming communication technologies and collective action demands recognizing how such technologies infuse specific protest ecologies. This includes looking beyond informational functions to the role of social media as organizing mechanisms and recognizing that traces of these media may reflect larger organizational schemes. Three points become salient in the case of Twitter against this background: (a) Twitter streams represent crosscutting networking mechanisms in a protest ecology, (b) they embed and are embedded in various kinds of gatekeeping processes, and (c) they reflect changing dynamics in the ecology over time. The authors illustrate their argument with reference to two hashtags used in the protests around the 2009 United Nations Climate Summit in Copenhagen.

The year 2009 was the year social media moved to the front line in a variety of national and transnational protests. Activists, police, and mass media announced their intent to step up use of social technology to coordinate, communicate, and monitor the G20 London Summit protests (Ward, 2009); Evgeny Morozov commented on "Moldova's Twitter Revolution" (Morozov, 2009a); and soon it was proclaimed that the Iranian revolution would be tweeted (Sullivan, 2009). As the early euphoria over the events in Iran was tempered, the debate instead came to center on whether and how new media have "real consequences for contentious politics" (Aday et al., 2010, p. 5). In general, however, "real" consequences continued to be measured in terms of pro-democratic institutional outcomes, and "new media" often boiled down to Twitter.

Sweeping assumptions and generalizations are not helpful starting points for examining the relation between social media and contentious collective action, much less for illuminating how social technologies operate in specific contexts with specific effects. Looking beyond their obvious function as means of sending and receiving messages, we argue for the importance of analyzing social technologies both as organizing mechanisms in complex collective action ecologies and as reflections of larger organizational schemes. Toward this end, we propose an approach that locates Twitter and other social technologies in diverse contexts of use while opening up for more focused assessments of the differing roles these media might play. We illustrate our argument with reference to two hashtags that were used in a family of protests leading up to the 15th United Nations Conference of the Parties on Climate Change (COP15) which took place in Copenhagen between the 7th and the 18th of December 2009. 


\section{Contextualizing Twitter Revolutions}

The debate about the 2009 Twitter Revolutions at base concerned whether Twitter triggers revolutions, and whether twittered uprisings are effective. This (pre-Egypt) discussion included focus on two issues: the uses of Twitter for publicizing local causes to distant audiences, and its importance in logistical communication among protesters on the ground. Enthusiasts claimed positive effect on both counts; critics played these same claims down.

In the first area of debate, optimistic accounts of protesters' ability to disseminate information to outsiders (thereby granting unprecedented insight into events on the ground to journalists and citizens alike) were answered with challenges to the reliability and representativeness of tweeted sources (A. Fisher 2010; Morozov 2009b). Moreover, questions remain about the value of Twitter streams in relation to professional journalism (Jewitt, 2009; cf. Arceneaux \& Schmitz Weiss 2010), and the general public's ability to deal with information overload (A. Fisher 2010; Morozov 2009b).

The other track revolved around Twitter's ability to facilitate activists' internal communication for the purposes of logistical coordination. The volume and the representative nature of the tweeters were again called into question. Voluble twitterers might not be the same people who are organizing the protests on the ground, who presumably prefer more secure means of communication (Esfandiari, 2010). Further, facilitated coordination is likely to benefit all kinds of actors, from state security forces to pro-regime supporters to genocidal mobs (Cascio, 2009; Morozov, 2009b; Palfrey, Etling, \& Faris, 2009). Questioning the implied link between sheer connectivity and political effectiveness, Gladwell (2010) argued that digitally networked activism fails to generate committed collective action when the going gets tough. He characterized social media activism in terms of weak ties and horizontal decentralized organization and contrasted this unfavorably with the strong ties and centralized hierarchical organization which marked key junctures in the Civil Rights Movement. Digitally networked action, Gladwell (2010) concluded, is ill-equipped to bring about systemic change.

It is clear that more nuanced theory and analysis is needed in order to develop realistic ways of thinking about the role of communication technologies in the transformation of contentious politics and, ultimately, the effectiveness of such politics. As long as the debate remains anchored in anecdotal evidence and sweeping generality, there is little reason to believe we are analyzing social deployments of technology adequately, let alone establishing decidable grounds for assessing their effects. On top of this, moreover, central starting points in the debate have been misleading.

One of the important analytical fallacies in the debate about social media and contentious politics has been to abstract new social media out of more complex contexts. It is important to note that there are two variations on this fallacy, both of which concern the framing of the debate as much as the dearth of fine-grained empirical analysis. The first is the tendency to isolate social media such as Twitter and Facebook from the broader technological and social contexts in which they operate. 
Single technologies risk becoming fetishized and personified. There is also a risk that the defining political features of the technology may become assumed rather than discovered. In the Twitter Revolutions debate, commentators' periodic cautions not to exaggerate the role of facilitated information sharing in regime change (e.g., Eaves, 2009) underscored how the discussion tended to approach Twitter as specifically an information communication device, focusing on the quality of the information flows on the one hand and its mobilizing promise on the other. Yet, it is not clear what evidence limits Twitter to creating external information flows or exchanging logistical information among dissidents. Although these are not unreasonable things to look for, they are static rather than dynamic categories.

The second variation of the abstraction fallacy is to extract Twitter use from its broader political context. On the one hand, it is sensible to recognize that there are likely to be multiple actors, levels and areas of use to be considered in any particular case. Aday et al. (2010), for example, discern distinct levels at which new media may have mattered in the case of the postelection protests in Iran. On the other hand, it is also important to note that the framing of the debate begs questions about how best to conceive of political action, effect and the role of social technologies in particular political events. Pulling any social media out of context and asking to what extent it facilitates actions such as those undertaken by the 1960s Civil Rights Movement, as Gladwell does, is far removed from trying to understand contentious politics in late modern societies and the fine grained communication mechanisms contributing to its organization. As Jussi Parikka (2010) put it:

[... ] while Gladwell is completely correct in saying that the form of politics that is attached to such practices is far from the way we think of politics in the heritage of the social activist movements of 60s and 70s, he himself does not bother mentioning that of course, that should be the start point of the argument, not its conclusion.

The various ways of isolating Twitter place an undue burden of expectations (e.g., to cause revolutions) on what is just one of many factors in the contemporary political communication and organization repertoire. Moreover, extracting single elements from more complex communication processes involving many actors and technologies may misrepresent the political action and dynamics of the case at hand. By contrast, analyzing social technologies in the context of evolving collective action sequences may enable us to move beyond seeing just a message stream shared among participants, to begin understanding the role of these technologies as organizing mechanisms, and, equally interesting, using them as windows on the larger protest ecology itself.

\section{The Several Sides of Twitter in the Protest Action Ecology}

The previous section suggested that technologies such as Twitter are likely to be deeply embedded in the surrounding protest ecologies in which they operate. Recognizing this point may be important 
particularly when dealing with complex protest spaces: that is, contexts in which multiple actors (from individuals to organizations to coalitions) with different ideational and organizational ideologies coconstitute the protest space, and in which social technologies are perceived as offering a flexible means for both organizers and individuals to access and navigate that space. Widening our focus beyond contention under authoritarian regimes, such complexity has been argued to characterize protest in post-industrialized democracies (Bennett, Breunig, \& Givens, 2008). It also specifically describes the protests in London and Copenhagen about the COP15 Summit, which we will use to illustrate our argument. Putting Twitter in context in such cases involves not only looking at ever more technologies, actors and uses but approaching it from the perspective of its roles in the protest ecology. There are at least two important and complementary aspects to Twitter from this perspective: its role as both networking agent in and window on the protest space.

From the first perspective, Twitter is interesting as an organizing mechanism within the specific protest ecology. As well as transmitting information, networked protest spaces constitute negotiated spheres of individual and collective agency. As digital and social media become increasingly prominent, they too become networking agents (or actants; Latour, 2005) within the protest space. The presence or absence of affordances and discourses constrain and enable action in these often densely linked and navigable spaces, at the same time as they help structure relations among different actors, issues, and events (Foot \& Schneider, 2006). Such networks of people and technologies can operate differently in terms of coherence, sustainability, and effectiveness of associated actions, and this invites attention to how collective action spaces develop and play out under different circumstances (cf. Langlois, McKelvey, Elmer, \& Werbin, 2009). Digitally networked protest spaces often involve dense webs of technologies deployed by different actors, so Twitter is one of potentially many digital mechanisms that co-constitute and co-configure the protest space.

From the second perspective, Twitter streams may reveal interesting features of the protest ecology's wider composition, and in particular something of the organizational scheme in which they are embedded. This may, among other things, indicate something of the larger network of relations involved in a particular event, even if it does not tell the whole story about them (cf. Huberman, Romero, \& Wu, 2009). One alternative is to analyze the users contributing to a stream (where these are identifiable; Boyd \& Ellison, 2007); another is to turn the stream inside out to look at who and what is linked to rather than who is posting. The organizations and social media linked in tweets reveal a sample of the organizations, information sources, and social networking sites pertinent to a particular protest ecology. For example, link data from the climate change protests that we discuss later reveal how different organizations (from advocacy organizations to government agencies) and information sources (e.g., the BBC, the United Nations News Center, The Brookings Institution, bloggers) become engaged with activist networks at various stages of protest events. The contexts of these links include participants assessing the mass media effect of real time actions, sharing think tank material, and recounting their own experiences at events. 
This twofold approach to Twitter in digitally networked protests can only be indicative; it cannot roll out a definitive map of the protest space. What is more, Twitter may play very different roles in different ecologies. With these conditions in mind, we nevertheless distinguish three points of focus around which it may be possible to develop fruitful models:

- Twitter streams can be crosscutting networking mechanisms. Twitter streams can (although do not always) attract diverse players, from individuals to organizations, and include contributors and followers from afar and in the midst of the action. In this light, they may be approached as transmission belts as they cut across and connect diverse networks, actors and locations in an action space. The networks at play in a Twitter stream may in part be revealed by such features as the links embedded in tweets.

- Twitter streams embed and are embedded in gatekeeping processes. There are different modes for managing the flow of links and other inputs embedded within a Twitter stream. A stream may allow glimpses of more classic gatekeeping where, for example, the content of a link is removed at source. More important, however, gatekeeping management is also visible within the stream itself in terms of which (and how many) agents introduce particular kinds of links, or amplify cues such as @-ness replies and RT retweets. Although hashtags are open to all users, such management may become more centralized when streams are populated mainly by one or a few organizations whose members have particular organizational uses in mind, such as rallying demonstrators for a specific event. By contrast, hashtags that are dominated by diverse crowds may result in chaotic streams with links and directives that seem not to connect with each other. In still other cases, such in-stream crowdsourced gatekeeping can introduce fairly sustained and rich organizational resources in far-flung protest ecologies.

- Changing organizational dynamics over time. As we shift the analytical focus in these directions, it is important to remember that data from Twitter streams only contain a slice of the collective action space, and that what the slice looks like may change as other elements in the evolving environment interact with the users and managers of the stream. Depending on where one cuts into a Twitter stream, then, one may find different actors and different kinds of activity going on, from rallying in the midst of a demonstration, to debriefing and planning for next events at later stages. In these ways, some streams may operate as relatively long-running epistemic communities, rich with information and analysis, whereas others may serve as brief beacons of information and logistics contributing to the orchestration of a particular action within a bounded time frame.

We discuss these three points individually in the following sections, illustrating our argument with reference to hashtags in two climate change marches. Both marches were part of a family of national and transnational protests leading up to the COP15 conference, and both in their own way exemplify complex protest spaces. The first constituted a single coalition-centred protest space leading up to a march held in London and Glasgow 1 week before the COP15, on December 5, 2009. The 
Wave march was organized by Stop Climate Chaos Coalition (SCCC), a tight coalition supported by organizations such as Christian Aid, Tearfund, Oxfam, Greenpeace, World Wildlife Fund, and the Catholic Agency For Overseas Development. Part of the complexity of this case involves the balance of communication between the organizations and potential demonstrators as the coalition and its supporter organizations used a variety of social media platforms to organize and mobilize demonstrators to urge the national government to hold the line on carbon reduction targets at the Copenhagen conference. Fifty thousand people turned out to the march, making this the largest climate protest in the United Kingdom, and in the view of the organizers at the time, "the biggest climate change march in the world ever!" (Stop Climate Chaos Coalition, 2009a).

The other case is the more self-organized protest space found in Copenhagen during the conference itself. The conference drew a diverse crowd of international protest actors, some strictly coordinated and others less so. Part of the complexity of this case was the sharing and partitioning of the protest space between the various actors (Reitan, 2011). There was more than a week of protest activities corresponding to the duration of the COP15 conference, with events of different kinds associated with different groups. The main demonstration, the Global Day of Action ("Climate March at the Climate Summit”) took place on December 12, 2009, and an estimated 100,000 people took part (D. Fisher, 2010). Despite the astonishing numbers, this event had been relatively loosely coordinated by the Danish coalition 12Dec09, which cited a support base of 538 organizations from 67 countries (12Dec09.dk). Analyzing hashtag streams associated with the two respective protests from the perspective of our three points indicates interestingly different yet similar dynamics in each ecology, as well as suggesting differing roles for Twitter within them.

\section{Twitter as Crosscutting Networking Mechanisms}

A Twitter stream can be conceived as a cross-cutting transmission belt connecting diverse users, uses and different temporal and spatial regions of the protest space. The Twitter hashtag, as opposed to profile feed, is particularly interesting from the perspective of this article as it suggests the contours of a network cutting across (and beyond) the protest space. Unlike the profile feed, which is controlled by a particular actor, the community-generated hashtag convention allows anyone to use a hashtag for any tweeted message whatsoever. Hashtagged messages - and their retweets-may disperse widely in unpremeditated combinations across a variety of feeds and networks.

Hyperlinks play an important role within these hashtag streams. In line with the perspective sketched in the previous section, we suggest looking at links not just with respect to information flow but also in their role as organizing mechanisms, and more abstractly as windows on surrounding players and links among diverse information flows. In the first instance, this entails viewing links from the perspective of how they may structure and alert members of social networks to particular slices of the protest space. This draws on previous work that has explored how hyperlinks on organization websites can play a structuring role, enabling and constraining action in protest space, and how they 
shape a protest space in the way they are used to construct and advertise alliances between different actors (Foot \& Schneider, 2006; Rogers, 2004; cf. Weber, Chung, \& Park, forthcoming). It also entails approaching twittered hyperlinks with attention to what they reveal about the networked ecology of the agents involved. Although user information reveals one important side of the protest ecology, we here concentrate on turning the Twitter stream inside out to shed light on actors and sites that in this manner become or are revealed to be part of the protest space.

This dual approach can be illustrated with reference to two hashtags related to the climate change protests outlined earlier. Each hashtag was the most prominent in its protest. \#Thewave was launched by the SCCC that co-ordinated the UK protest. \#Cop15, by contrast, is an interesting example of an emergent self-organizing stream that was not centred on one organization or coalition. Both involved a variety of organizations and individuals operating in the midst of the demonstrations as well as from a distance. What is more interesting is what these actors made of the stream: What kinds of sites were linked to and what do the different patterns of links tell us about the underlying organizational logic of the protest ecology?

\#Thewave hashtag, as stated, was launched by the SCCC as part of a wider campaign to mobilize and publicize The Wave march. The number of tweets sent with \#thewave amounted to more than 2,500 from the point at which it trended in the United Kingdom on the morning of the protest to its dying out a few days later. The use of the hashtag ceased shortly after the protest (but was later reactivated in a nonrelated context). The \#cop15, a multi-language hashtag of unclear origin, became one of the most used and tracked streams relating to the COP15 conference as well as the associated protesting (Boynton, 2010). This hashtag was used prolifically by various actors across several languages and locations for various purposes, including the Danish government as conference host, individual protesters, bloggers, and advocacy organizations. It was in use months before the conference and continues (at a far lower volume) at the time of this writing. By the end of December 2009, roughly 100,000 \#cop15 hashtagged tweets had been logged (Twapperkeeper.com).

Because there were thousands of tweets in each of our hashtags, we took random samples. Every tenth tweet was sampled from each stream for the date selected. One clear difference in the two streams was that \#thewave involved a burst of activity around the day of the protest, whereas \#cop15 had a much more extended life before, during and after the main protest day. Thus, we were able to compare the two streams on the day of the protest marches and also sample \#cop15 on other dates to assess dynamics over time. On the day of the main demonstrations, \#cop15 included 3,251 tweets, giving a sample of 325 . Because \#thewave was more exclusively dedicated to the protest day itself, we sampled the single trend line that included the day of the protest and the few tweets of the days after, for a total of 2,529 tweets that resulted in a sample of 253 . 


\begin{tabular}{lll}
\hline Link level & $\begin{array}{l}\text { \#The Wave (Dec 5 - 8 2009) } \\
\text { sample } \boldsymbol{n}=\mathbf{2 5 3}\end{array}$ & $\begin{array}{l}\text { \#cop15 (Dec 12 2009) } \\
\text { sample } \boldsymbol{n}=\mathbf{3 2 5}\end{array}$ \\
\hline $\begin{array}{l}\text { Percent of all tweets with } \\
\text { links }\end{array}$ & $39 \%(99)$ & $60.9 \%(198)$ \\
Mass & & \\
Mid & $15.15 \%(15)$ & $18.18 \%,(36)$ \\
Micro & $34.34 \%(34)$ & $56.56 \%(112)$ \\
Other/Broken & $33.33 \%(33)$ & $10.6(21)$ \\
\hline
\end{tabular}

Links are major elements in both streams on the day of the protest, but there are important differences in their volume and distribution. As shown in Table 1, links appeared in 39\% of \#thewave tweets, and fully $60.9 \%$ of the \#cop15 tweets (as we discuss in the dynamics analysis later, linking in the latter stream was in fact higher on other days). The volume and nature of linking in the Copenhagen protest hash as compared to the pre-Copenhagen UK protests suggests interesting things about the two protest ecologies in which the streams are embedded, and as we shall discuss further below, the differing roles Twitter plays in the two cases.

Our analysis tracked the different types of links that emerged in both streams. In the case of the continuing \#cop15 stream, we also followed how they may have changed over time. We discovered a media world that places the mass media at the margins, and elevates purveyors of social technology from nongovernmental organizations (NGOs) to Flickr to prominent roles. The breakdown of links on the day of the two protests also appears in Table 1. We categorized the links in terms of whether they pointed at mass media sites (e.g., BBC, Le Monde, The New York Times), middle media sites that exist primarily or only online yet receive large numbers of users (e.g., alternative news media, NGOs, government and corporate sites, environment and climate information sites, and prominent blogs such as Real Climate), and micromedia sites that reflect individual-level sites that are clearly personal in nature. In keeping with our focus on what elements were brought in through links, we made borderline decisions on the basis of where the content was created rather than who posted it (e.g., Al-Jazeera on YouTube would be coded as mass media; an NGO-posted twitpic would be coded as middle media; a personal or anonymous twitpic would be coded as micro level). This scheme builds on the model suggested by Peretti (2002) for tracking media flows across increasingly intertwined communication networks.

Table 1 shows that actors in the realm of middle media represent the dominant organization and information sites in both these slices of the protest ecology. Yet, a notable difference between the two streams has to do with how the links were further distributed within the middle and micro media categories. Within the middle media categories, links to NGO websites and NGO uses of social media rival links to mass media news actors in both streams: In \#thewave this NGO pattern constitutes $19.19 \%$ of all the links, and in \#cop15 on the day of the protest it constitutes $17.67 \%$ of all the links. 
In the \#cop15 similarly large numbers of links led either to alternative news media (e.g., Indymedia, Huffington Post) or think tanks and various kinds of climate information sites or institutes (e.g., Scientific Public Policy Institute, the Amazon Environmental Institute, Think Progress). Together these kinds of links add up to $18.18 \%$ of the total number of links, also equalling the mass-media linking rate in this stream. Meanwhile, governmental sites such as the conference host Denmark's COP15 website accounted for $13.13 \%$ of all links. Contributors to the \#cop15 hashtag in this way pooled organizational and information resources using the networking potential of middle media sites.

The links in \#thewave, by contrast, underscore the ways in which this hashtag centered on a physically copresent demonstration. Mid-level linking in this stream primarily led back to the coalition coordinating the march and its sponsoring organizations, and the microlevel links primarily presented depictions of the march itself. As we shall discuss further in the next section, \#thewave hashtag was used strategically by the SCCC to personalize the mobilization for the planned protest. Participants were encouraged to paint faces and hands blue to echo the environment association when they waved into cameras, and then to post photos from the demonstration. This seems to explain the strong linking to microlevel sites in this stream. Almost all of the microlevel links in this stream lead to twitpics or yfrog photos from the street march itself. A number of the middle level links also went to coalition organization photo pages, resulting in fully $44.32 \%$ of all links in \#thewave going to photos or photo galleries. This high rate can be compared with the lower presence of personal microlevel linking in the \#cop15 stream, which also had fewer photo links overall (only 14\%). This seemingly reflects how The Wave was oriented to a community of protesters who shared both geographic and ritualistic elements in their protest identifications via high levels of personally expressive content.

All of this suggests that linking is used differently in different protests, even ones belonging to the same family of collective action events (i.e., addressing the same issue, targeting the same actors, happening in the same time frame). Thinking about links as revealing elements of the protest ecology, we see a more personalized expressive experience reflected in The Wave given the encouragement by NGO facilitators to share personal experiences. The lower levels of NGO links in the Wave reflect an organizing coalition of NGOs that did not need to link back to themselves, but rather encouraged those being mobilized to link out to each other. By contrast, the large number of Copenhagen demonstrators and people following their activities from afar seemed to find it more useful to point to diverse NGOs and middle media information sites as resource hubs. The stream associated with the more selforganizing ecology in this sense sought out organizational and informational resources more than the organization-centred ecology.

\section{Gatekeeping Processes in the Twittered Protest Space}

A further important dimension along which different protest ecologies can be compared is the gatekeeping that distributes various types of actionable information to participants. While there is little agreement about the meaning of gatekeeping (Barzilai-Nahon, 2009), it here refers to what kinds of 
filters operate in a communication system, who or what agents control them, and what information they screen out and let through. As pointed out earlier, no one can control a hashtag stream in the sense of deleting messages. However, actors can contribute positively to the shape of a stream by, for example, introducing posts, links, amplifying retweets, and @-ness address (cf. Boyd, Golder, \& Lotan, 2010; Honeycutt \& Herring, 2009). We did analyze retweeting in the streams, but for reasons of space we here continue to focus on in-stream management in the form of linking. Broad comparisons between the two Twitter streams suggest that very different in-stream processes were at work. \#Thewave reflected a far more organization-centred and centrally managed protest space, while \#cop15 reflected a more decentralized crowdsourced scheme. What is remarkable is that both stayed fairly consistently on topic and displayed little violent disagreement.

As already indicated, \#thewave hashtag was launched and largely managed by the SCCC coalition coordinating the march. The SCCC and its supporter organizations used several digital technologies in a strategy of personalizing the mobilization around the march, enabling users to fill in details in the protest narrative and to customize their digital interactions with the coalition. The SCCC initiated several twitter storm campaigns before and during the protest. One storm on November 5, 2009, highlighted the official launch of The Wave website. The organizers encouraged followers to "Tell all your friends and retweet, retweet, retweet! See you on \#TheWave." (Stop Climate Chaos Coalition, 2009b). The hashtag trended to second place among all Twitter streams in the United Kingdom during the march (Twirus UK). After the march, the SCCC no longer actively encouraged use of the hashtag, and use died out within days.

The SCCC strategy of personalizing their public communication meant running the risk of losing control over their message and brand (Bennett \& Segerberg, 2011; Gillan, Pickerill, \& Webster, 2008). Yet, \#thewave is a surprisingly orderly stream. The SCCC apparently did not try to discipline the contents of the \#thewave stream aside from for example encouraging retweeting. As expected, then, some of the sampled tweets publicize other actions, for example those that couple \#thewave with \#copout (referring to a separate direct action protest organized by Climate Camp London). Yet, there were only a few of them, and there is only one explicitly critical tweet in the entire sample: "People on \#thewave screaming bloody murder are the same kids who used to take the piss out of my family for growing veg \& mending clothes." Again, \#thewave clearly reflected its function as a rallying and mobilizing mechanism centred on the physically co-present demonstration. As discussed in the previous section, links predominantly led to the sponsoring organizations or the photos of people attending the demonstration. Coded for content, the stream scored highly in tweets that were either describing the real time event $(68 \%)$, or expressing solidarity with the protest $(28.9 \%)$. Logistical information (where to go, what to do) was less prevalent (11.1\%), suggesting that logistical support was being provided through other sources. It is interesting to note that the coalition and its supporter organizations represent only $24 / 253$ or $9.48 \%$ of the users posting in our sample, but this proved enough to shape the arc of the stream. 
In contrast with \#thewave \#cop15 was self-organizing, and yet it too turns out to be surprisingly ordered. We have not found evidence of any attempt to launch this hash amongst the central organizations related to the conference or the protest march. The 12Dec09 coalition, the coordinators of the march, created a profile Twitter feed (@12dec09), yet posted few entries (barely filling one page) and did not use any hashtags on this feed. The conference host government's Ministry of Foreign Affairs used \#cop15 in its profile feed @cop15, but did not indicate any sense of ownership, nor did they appear as a dominant user in our sample.

Despite strategic deployment by a few prominent actors, the bulk of the stream reveals a general absence of dominating gatekeepers around the time of the protest. In contrast with the SCCC in \#thewave, there were relatively few identifiable organizations tweeting in \#cop15 under their own name. In other words, the \#cop15 management during the protest seems to be more crowdsourced, with links to a wide variety of governmental and civil society organizations, as discussed in the previous section. The \#cop15 also did not seem to serve the steadily managed role of rally mechanism that was seen in \#thewave. Coded for content on the day of the protest, the \#cop15 scores fairly highly for real time descriptions of the event $(61.2 \%)$ but low on expressions of solidarity (13.2\%) and logistical messages (6.2\%). The low level of logistics suggests once again that the real-time orchestration of demonstrations occurred elsewhere, and that the \#cop15 instead offered windows on the events and other resources for the actors to share.

This comparison suggests that in-stream gatekeeping in a self-organizing crowdsourced stream need not be less coherent than more centralized organization management of the sort we find in \#thewave. It also appears that different streams can serve different organizational roles and stay focused. The large volumes of \#cop15 tweets tend to keep to the general issues at hand: climate change, the conference, protesting the conference. Few messages express criticism of the other tweets being disseminated through the hashtag. Some of the environmental information sites belong to climate sceptics, yet there is little disagreement or abusive language voiced within the stream about the issues at stake. As we found in a separate study, this is unlike the character of the \#G20 stream used during the G20 Pittsburgh Summit protests in the fall of 2009, in which protesters, antiprotesters, and disgruntled locals struggled via Twitter over the rightful uses of the streets of Pittsburgh.

The self-organizing character of the stream also reveals how various social technologies can adapt to the temporal frame of contentious political activities. One clear difference between \#thewave and \#cop15 is that the latter ran alongside the 10 days of protester activities, including various direct action and civil disobedience events, several educational forums, religious services, and the main demonstration (http:// $\quad$ www.climateimc.org/en/original-news/2009/11/09/1ist-cop15copenhagenprotests- and-events). Figure 1 shows that there were several days with thousands of tweets, indicating that \#cop15 was far more than just a rallying or logistical communication aid during the demonstration itself. 


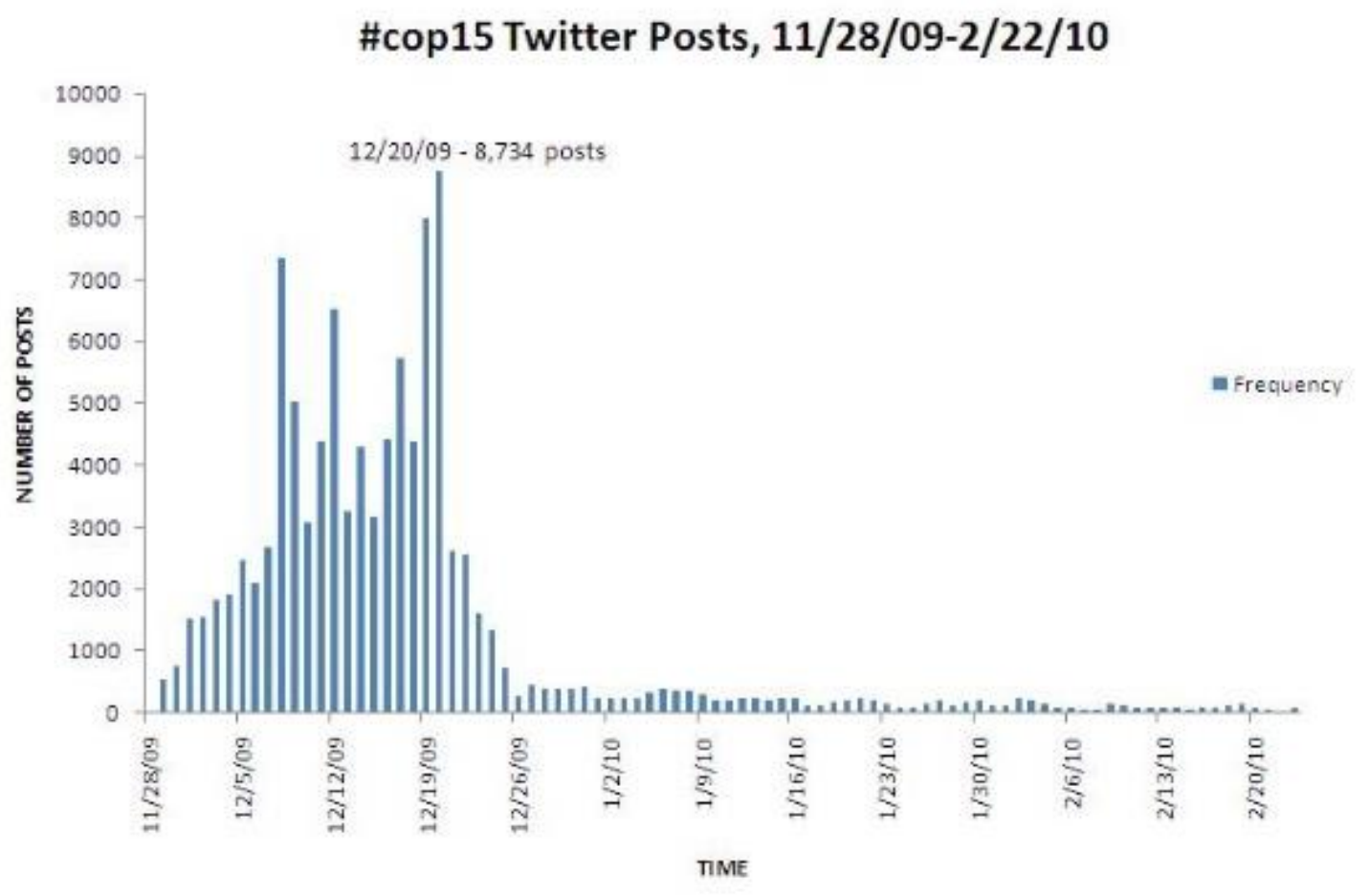

The crowd-as-gatekeeper (in the sense of emphasizing particular themes and creating particular resource and organizational links) also repurposed the \#cop15 stream following the end of the protests. For unlike \#thewave, the \#cop15 stream did not come to an abrupt halt. A year after the Copenhagen events, the stream gradually merged with others in a kind of handoff to the COP16. Although the numbers of tweets dwindled, the relative level of linking increased after the protest (even as the diversity of users seemed to decrease). It appears that a kind of resource-focused epistemic community was created with links to a variety of organizations and bloggers offering information and organizational resources across a global network. The very different dynamics of our two cases highlight our final point: the importance of recognizing the potentially changing nature of hashtag streams embedded in different collective action contexts and at different points in those contexts over time.

\section{How Twitter Reflects Changing Dynamics in Protest Ecologies}

Another clear organizational feature of Twitter streams in protest ecologies is their capacity to shift organizational functions over time. As Herwig, Kossats, and Mark (2010) observe in the case of the 2009 \#unibrennt student protests in Vienna, these twittered network patterns appear to be "permanently beta," open to change in organizational character (cf. Neff \& Stark, 2003). In some cases, as in \#the wave which served to rally participation for a particular event, the organizational pattern entails disappearing when the immediate function has been outlived. \#cop 15, on the other 
hand, evolved through several different organizational phases in the time before and after the Copenhagen demonstrations. Different patterns of use emerge depending on where one cuts into the stream. However, one general difference emerges. The \#cop15 stream, embedded in a more selforganizing and wider protest space, increasingly "seeks out" resources as the remaining users increasingly link to blogs and institutional sites. This resource seeking in a way stabilizes the organization of the stream. By contrast, the more centralized coalition facilitating a demonstration via \#thewave may have provided support resources directly through member organizations communicating with their affiliated publics.

We traced the \#cop15 stream from one week prior to the December 12 protest to one month after the protest. Shortly after December 12, it decreases to a small but steady stream. It continues, and, as noted, transitions. As Table 2 shows, the level of linking rises in the \#cop15 over time, dipping during the day of the protest while other uses momentarily rose. (Note that multiple codes were permitted, so that a tweet could, for example, contain a solidarity message and a link, just a solidarity message, or just a link.) After the protest, the numbers of tweets containing links rose to an extraordinary $88 \%$ (fully 73 of our late stream sample of 83 tweets). The relative absence of central coordination in the Copenhagen protests and hash may account for the higher levels of links embedded in the tweets; participants increasingly point each other to organizations and other resources afterwards as well.

TABLE 2 Shifting Use Patterns of \#cop15 Over Time

\begin{tabular}{llll}
\hline & Dec 3, $\boldsymbol{n}=\mathbf{1 9 3}$ & Dec 12, $\boldsymbol{n}=\mathbf{3 2 5}$ & Jan 12 \& 19, $\boldsymbol{n}=\mathbf{8 3}$ \\
\hline Description & $24.4 \%(47)$ & $61.2 \%(199)$ & $25.3 \%(21)$ \\
Solidarity & $5.2 \%(10)$ & $13.2 \%(43)$ & $3.6 \%(3)$ \\
Logistical & $10.9 \%(21)$ & $6.2 \%(20)$ & $6 \%(5)$ \\
Link & $78.2 \%(151)$ & $60.9 \%(198)$ & $87.95 \%(73)$ \\
Other & $4.7 \%(9)$ & $9.8 \%(192)$ & $6 \%(5)$ \\
\hline
\end{tabular}

The main dynamic is that the proportion of tweets containing links soared as the stream diminished in volume. Yet, given our observation about the tendency of this stream to seek resources in its links, it is also interesting from the perspective of the transmission belts analysis discussed earlier that the general distribution of these patterns is fairly constant at different points in the arc of the stream. Even as the media level of tweets (mass, middle, and micro) differed in our two cases at the same point in protest time (recall the high use of micromedia and photos in \#thewave, and the higher middle media linking in \#cop15), the overwhelming tendency across different phases of \#cop15 was to connect protesters to middle media sites (see Table 3). 


\begin{tabular}{llll}
\hline & \#Cop15, Dec 3 & \#Cop15, Dec 12 & \#Cop15, Jan 12, 19 \\
$n=193$ & $n=325$ & $\boldsymbol{n}=\mathbf{8 3}$ \\
Link level & Links: 151/193 (78\%) & Links: 198/325 (61\%) & Links:73/83 (88\%) \\
\hline Mass & $21.19 \%(32)$ & $18.18 \%(36)$ & $17.8 \%(13)$ \\
Mid & $68.87 \%(104)$ & $56.56 \%(112)$ & $65.75 \%(48)$ \\
Micro & $4.6 \%(7)$ & $10.6 \%(21)$ & $8.2 \%(6)$ \\
Other/Broken & $5.29 \%(8)$ & $14.64 \%(29)$ & $8.2 \%(6)$ \\
\hline
\end{tabular}

The end of stream dynamics we observe with \#cop15 also bears on the earlier gatekeeping discussion. As we traced the later stages of the \#cop15 stream we noted a shift in the balance of actors in terms of who participated at what rate. Analysis of the stream one month after the protest revealed a continuing diversity in the range of actors, even as there were some shifts (e.g., NGOs becoming somewhat more prominent and government sites somewhat less). However, analysis by "What the Hashtag?!" indicates that by the time almost a year had lapsed, a few single actors had come to dominate the stream. In October 2010, What the Hashtag?! reported that $80.3 \%$ of the 71 \#cop15 tweets in the previous week had come from the "top 10" contributors to the stream, chief of which was @Climatebloggers, a profile feed aggregating the posts of a delimited network of bloggers covering the COP15 (including Huffington Post and Oxfam).

The dynamic shifted again at the end of the life of \#cop15 as participants apparently shifted to other hashtags such as the \#cop16 in anticipation of the next conference. The \#cop16 not only had a greater volume of tweets during the same October 2010 time period (994), but a far greater number and proportion of distinct contributors (512). Only 20.8\% of these \#cop16 users came from the "top 10" (chief of which was @cop16; What the Hashtag?!, 2010). The transition to \#cop16 may thus mark a return to the more distributed, crowdsourced management pattern described in earlier phases of the \#cop15 earlier. Nevertheless, the dominance of the late phase of the old stream by higher resource actors (e.g., middle media bloggers) seems important both for stabilizing a weak stream and facilitating its handoff to the next.

\section{Conclusions}

The Twitter Revolutions of 2009 reignited the question of whether new social media have any real effect on contentious politics. This article has argued that critically examining the relation between transforming conditions for communication and collective action demands recognition of the ways in which social technologies infuse specific protest ecologies. The immediate question from this perspective is neither what Twitter does to contentious politics nor what specific actors do with Twitter. Rather, this approach looks to the roles of social technologies as organizing mechanisms (as organizational agents), and the traces of these technologies that may reflect larger organizational schemes in a protest ecology (as windows). 
The article has further suggested that although different protest ecologies are expected to be different, three dimensions facilitate analysis and comparison over different cases: the way Twitter streams represent networking mechanisms crosscutting the protest ecology; how they embed and are embedded in various kinds of gatekeeping processes; and how they reflect changing dynamics in the ecology over time. Illustrating this argument in the context of two different protests we saw indications of some of the specifics of the respective ecologies and their dynamics, as well as differing roles played by the twittering within these ecologies. Among other things, it appears that while the \#thewave was successfully harnessed as an amplifying mobilization and publicity resource by a set of central actors, \#cop15 indicated how more self-organizing streams may seek resources in different ways from organization-centred ones.

As a note of caution, it should be stressed that this approach yields indications rather than full descriptions, and that the illustrative analyses presented here are limited. Future studies would need to delve even deeper into these hashtags, including reintroducing users into the analysis to ascertain who does what and helps create what kinds of resources. In many episodes of contentious action, moreover, a Twitter hashtag is just one of many digital media mechanisms operating to bring publics together to act in concerted or less organized ways: future research would also need to re-embed these hashtags more fully into the complex episodes of digitally networked contentious politics in which they appear.

An overarching point of these analyses is that viewing Twitter as a communication update service may not distinguish the most intriguing dimensions of Twitter in contentious politics. Twitter reveals a variety of interesting clues about different kinds of protests: What kinds of organizations and resources are operating in the environment, how the players organize different gatekeeping mechanisms, and how those gatekeeping processes may help explain changing linking and user dynamics of hashtags over time. Yet, such features may be difficult to evaluate if we too closely follow unexamined assumptions about where and what the politically relevant effect ought to be. Will the revolution be twittered? It is more important to ask how social media embed and engage different ecologies of dissent.

\section{Acknowledgments}

This article builds on work supported by Swedish Research Council grants Dnr 435-2007-1123 and Dnr 421-2010-2303. The authors thank Nathan Johnson, Allison Rank, and Marianne Goldin for their research assistance.

\section{References}

Aday, S., Farrell, H., Lynch, M., Sides, J., Kelly, J., \& Zuckerman, E. (2010). Blogs and bullets: New media in contentious politics. Washington, DC: U.S. Institute of Peace. 
Arceneaux, N., \& Schmitz Weiss, A. (2010). Seems stupid until you try it: Press coverage of Twitter, 2006-9. New Media and Society, 12(8), 1262-1279.

Barzilai-Nahon, K. (2009). Gatekeeping: A critical review. Annual Review of Information Science and Technology, 43, 433-478.

Bennett, W. L., Breunig, C., \& Givens, T. (2008). Communication and political mobilization: Digital media use and protest organization among anti-Iraq war demonstrators in the U.S. Political Communication, 25, 269-289.

Bennett, W. L., \& Segerberg, A. (2011). Digital media and the personalization of collective action: Social technology and the organization of protests against the global economic crisis. Information, Communication \& Society, in press.

Boyd, D., \& Ellison, N. (2007). Social network sites: Definition, history, and scholarship. Journal of Computer-Mediated Communication, 13(1), 210-230.

Boyd, D., Golder, S., \& Lotan, G. (2010, January). Tweet tweet retweet: Conversational aspects of retweeting on Twitter. Proceedings of HICSS-43, Kauai, HI.

Boynton, G. R. (2010, September). COP15-Voice. Paper presented at the Internet, Politics, Policy 2010: An Impact Assessment, Oxford Internet Institute, Oxford, UK.

Cascio, J. (2009). The dark side of twittering a revolution, June 17. Fast Company. Retrieved from http://www.fastcompany.com/blog/jamais-cascio/open-future/twitteringrevolution

Eaves, E. (2009, June 19). Information is overrated: Twitter's not gonna change our world. Forbes. Retrieved from http://www.forbes.com/2009/06/18/foreignpolicy-iranvietnam-rwanda-opinions-columnists-social-media-twitter.html

Esfandiari, G. (2010, June 7). The Twitter devolution. Foreign Policy. Retrieved from http://www.foreignpolicy.com/articles/2010/06/07/the_twitter_revolution_that_wasnt

Fisher, A. (2010). Bullets with butterfly wings: Tweets, protest networks, and the Iranian election. In Y. Kamalipour (Ed.), Media, power, and politics in the digital age: The 2009 Presidential election uprising in Iran (pp. 105-118). Lanham, MD: Rowman and Littlefield.

Fisher, D. (2010). COP-15 in Copenhagen: How the merging of movements left civil society out in the cold. Global Environmental Politics, 10(2), 11-17.

Foot, K., \& Schneider, S. (2006). Web campaigning. Cambridge, MA: M.I.T. Press.

Gillan, K., Pickerill, J., \& Webster, F. (2008). Anti-war activism: New media and protest in the information age. Basingstoke, England: Palgrave Macmillan. 
Gladwell, M. (2010, October 4). Small change: Why the revolution will not be tweeted. The New Yorker.

Herwig, J., Kossatz, M., \& Mark, V. (2010). \#unibrennt mit internet. Beobachtungen zu einer sich ändernden Protestqualität. [The uni's burning via internet: Observations on the changing nature of protest.] In S. Heissenberger, V.

Mark, S. Schramm, P. Sniesko, \& R. Süss (Eds.), Uni Brennt. Grundsätzliches, Kritisches, Atmospherisches [The university is burning: Basics, critique, atmosphere] (pp. 210221), Vienna, Austria: Verlag Turia + Kant.

Honeycutt, C., \& Herring, S. (2009). Beyond microblogging: Conversation and collaboration via Twitter. Proceedings of the 42nd Hawai'i International Conference on System Sciences, Los Alamitos CA: IEEE Press.

Huberman, B., Romero, D., \& Wu, F. (2009). Social Networks that Matter: Twitter under the Microscope. First Monday, 14(1-5). Retrieved from http://firstmonday.org/htbin/cgiwrap/bin/ojs/index.php/fm/article/viewArticle/2317/20 $\underline{63}$

Jewitt, R. (2009). The trouble with twittering: Integrating social media into mainstream news. International Journal of Media and Cultural Politics, 5(3), 233-240.

Langlois, G., McKelvey, F., Elmer, G., \& Werbin, K. (2009). Mapping commercial Web 2.0 worlds: Towards a new critical ontogenesis. Fibreculture, 14. Retrieved from http://fourteen.fibreculturejournal.org/fcj-095-mapping-commercial-web-2-0-worldstowards-a-new-critical-ontogenesis/

Latour, B. (2005). Reassembling the social: An introduction to actor-network-theory. Oxford, England: Oxford University Press.

Morozov, E. (2009a). Moldova's Twitter revolution. Foreign Policy. Retrieved from http://neteffect.foreignpolicy.com/posts/2009/04/07/moldovas_twitter_revolution Morozov, E. (2009b). Iran: Downside to the “Twitter Revolution.” Dissent, 56(4), 10-14.

Neff, G., \& Stark, D. (2003). Permanently beta: Responsive organization in the Internet era. In P. Howard \& S. Jones (Eds.), The Internet and American life (pp. 173-188). Thousand Oaks, CA: Sage.

Palfrey, J., Etling, B., \& Farris, R. (2009, June 21). Reading Twitter in Tehran? Why the real revolution is on the streets - and offline. The Washington Post.

Parikka, J. (2010). Malcolm Gladwell and the (end) for something that never started? Retrieved from 
http://www.networkpolitics.org/blogs/jussiparikka/03/october/2010/malcolmgladwell-and-end-something-never-started-networkpolitics

Peretti, J. (2002). Culture jamming, memes, social networks, and the emerging media ecology: The "Nike sweatshop email" as object to think with. Retrieved from http://depts.washington.edu/ccce/polcommcampaigns/peretti.html

Reitan, R. (2011). Coordinated power in contemporary leftist activism. In T. Olesen (Ed.), Power and transnational activism (pp. 51-71). London, England: Routledge.

Rogers, R. (2004). Information politics on the web. Cambridge, MA: MIT Press.

Stop Climate Chaos Coalition. (2009a). Retrieved from http://www.stopclimatechaos.org/the$\underline{\text { wave }}$

Stop Climate Chaos Coalition. (2009b). Retrieved from http://www.stopclimatechaos.org/twitterstorm

Sullivan, A. (2009). The Revolution will be Twittered. The Atlantic, 13 June 2009.

Ward, M. (2009, April 12). Twitter on the front line. BBC.

Weber, M, Chung, C., \& Park, H. (Eds.). (forthcoming). Special issue: The hyperlinked society: Understanding the changing nature of communication in online environments. Journal of Computer-Mediated Communication.

What the Hashtag?! (2010, October 27). Entries \#cop15, \#cop16. Retrieved from Wthashtag.com 